\title{
Fabienne Cusin-Berche, Les mots et leurs contextes
}

\section{Rachele Raus}

\section{(2) OpenEdition}

\section{Journals}

Édition électronique

URL : http://journals.openedition.org/studifrancesi/33938

DOI : $10.4000 /$ studifrancesi.33938

ISSN : 2427-5856

Éditeur

Rosenberg \& Sellier

\section{Édition imprimée}

Date de publication : 1 décembre 2005

Pagination : 696-697

ISSN : 0039-2944

\section{Référence électronique}

Rachele Raus, «Fabienne Cusin-Berche, Les mots et leurs contextes », Studi Francesi [En ligne], 147

(XLX | III) | 2005, mis en ligne le 30 novembre 2015, consulté le 20 avril 2021. URL : http://

journals.openedition.org/studifrancesi/33938; DOI : https://doi.org/10.4000/studifrancesi.33938

Ce document a été généré automatiquement le 20 avril 2021.

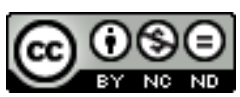

Studi Francesi è distribuita con Licenza Creative Commons Attribuzione - Non commerciale - Non opere derivate 4.0 Internazionale. 


\title{
Fabienne Cusin-Berche, Les mots et leurs contextes
}

\author{
Rachele Raus
}

\section{RÉFÉRENCE}

FABIENNE CUSIN-BERCHE, Les mots et leurs contextes, Paris, Presses de la Sorbonne Nouvelle, 2003, $201 \mathrm{pp}$.

Ce texte se compose de plusieurs articles de l'A. qui sont rassemblés en trois parties. Dans la première, il est question des mots entre langue et discours. En particulier, l'A. définit la notion d'unité lexicale en tant que composante du lexique, et la différencie du néologisme et du lexème en tant que «réalisation concrète et d'usage général» (p. 62). Dans la deuxième partie, s'inspirant d'une recherche menée pour EDF, l'A. analyse les mots dans les textes de spécialité. Notamment la redéfinition de l'agent en tant qu'acteur chez EDF amène une série de réflexions du point de vue de la langue (caractère non agentif du nom agent en contraste avec le caractère agentif du nom acteur) et des nécessités extra-linguistiques à la fois. Ainsi, le choix de décideur au lieu de décisionnaire dans le discours des entreprises «témoigneraient de l'existence d'un autre point de vue et d'une autre approche de l'entreprise» (p. 76). Dans la troisième partie, l'A. entreprend l'étude des mots d'un point de vue pragmatique. Plus particulièrement, elle s'intéresse aux mots serment et jurement par rapport aux fonds latins, d'où ces deux mots viennent, et par rapport aux actes auxquels ils renvoient. «Ainsi, peut-on dire que le serment est un acte individuel de nature sociale, dans la mesure où il expose l'individu à l'opprobre public» (p. 140). Le livre se termine sur l'étude des spécificités des courriers électroniques et de ce nouveau genre que l'A. appelle «genre messiel» (mot valise à partir de message et d'électronique), notamment par rapport à la nécessité de remodeler les catégories descriptives utilisées en analyse du discours pour observer les genres traditionnels. Au-delà de la richesse des données analysées, nous pouvons identifier au moins deux points fondamentaux dans tous les articles. D’abord le dépassement des oppositions traditionnelles langue-discours, 
terme-mot, contexte intérieur (cotexte) - contexte extérieur, mots pleins - mots vides... Ces couples sont plutôt considérés comme complémentaires, voire en continuum dans l'analyse diachronique du lexique. Ensuite, la proposition d'adopter des catégories homogènes, tout en redéfinissant les catégories traditionnelles (i.e. unité lexicale au lieu de mot, unité lexicale spécialisée au lieu de terme), ce qui supposent également une nouvelle approche en lexicologie. 